\title{
Labour Analgesia for Obstetricians: Epidurals and Beyond
}

\author{
Bryony Shelton* and Gamunu Ratnayake
}

Guy's and St Thomas' Hospital, London, UK

*Corresponding author: Bryony Shelton, Guy’s and St Thomas' Hospital, London, UK, E-mail: bryonyjshelton@gmail.com

Received: 28 Aug, 2020 | Accepted: 05 Oct, 2020 | Published: 29 Oct, 2020

Citation: Shelton B, Ratnayake G (2020) Labour Analgesia for Obstetricians: Epidurals and Beyond. Gynecol Women's Health Res 2(1): dx.doi. org/10.16966/2689-3096.116

Copyright: (C) 2020 Shelton B, et al. This is an open-access article distributed under the terms of the Creative Commons Attribution License, which permits unrestricted use, distribution, and reproduction in any medium, provided the original author and source are credited.

\begin{abstract}
Epidurals remain the gold standard for labour analgesia, especially during the current COVID-19 pandemic. They provide superior analgesia and lower the physiological and chemical responses to labour stress. However, they are associated with higher rates of instrumental delivery, maternal pyrexia and hypotension. Less invasive substitutes include nitrous oxide and parenteral opioids such as patient-controlled analgesia (PCA) with remifentanil. Non-pharmacological methods include hypobirthing and relaxation techniques, giving the mother a less medicalised labour experience. Newer regional techniques such as erector spinae and quadratus lumborum blocks are promising alternatives in those who cannot have or do not want an epidural. This review will outline the indications and contraindications to labour epidural use, and potential alternatives to an epidural.
\end{abstract}

\section{Introduction}

Pain during labour is experienced to varying degrees by all mothers. Its perceived intensity is a complex interplay between physiological and psychosocial factors [1]. 57-65\% of labouring mothers receive either analgesia or anaesthesia in the UK [2]. Analgesia can be non-pharmacological, such as hypnobirthing and acupuncture, or pharmacological. Pharmacological agents include inhaled or parenteral drugs, or administration via the neuraxial route. More recent techniques include a range of plane blocks using local anaesthetics. National Institute for Clinical Excellence (NICE) consensus remains that epidural anaesthesia is the most effective pain relief in labour [3]. This review aims to assist non-anaesthetists with considering different analgesic regimes for the labouring mother.

\section{Labour epidurals}

An epidural involves bathing the nerves that supply the uterus and birth canal with local anaesthetic (often in combination with an opiate like Fentanyl), as they exit the spine. The local anaesthetic is deposited just next to the sac that contains the cerebrospinal fluid (CSF). A catheter can be threaded at the same time, so that additional boluses of medication can be administered. A spinal injection is a one-off injection of local anaesthetic into the CSF. A combined spinalepidural (CSE) is a combination of both techniques, with a small dose of medication being injected into the CSF through a spinal needle for immediate relief, followed by a catheter being left in the epidural space for continuing administration. Epidural anaesthesia is used in around $33 \%$ of labouring women in the UK [4]. Pain from the first stage of labour involves dermatomes T10-L1, spreading more caudally to include S2-S4 nerve roots during the second stage of labour.

\section{Indications}

The primary indication for a labour epidural is the provision of analgesia as per maternal request. Epidurals can also be used to reduce physiological and chemical responses to labour in certain circumstances. Epidural mediated reduction in blood pressure may be helpful in hypertensive and pre-eclamptic patients, as well as in some underlying cardiac conditions where a reduction in after load is desirable. Siting of an epidural may also be advised in patients unsuitable for a general anaesthetic, such as those with potentially difficult airways for endotracheal intubation.

Anaesthetists sometimes use the term 'early' epidural, which refers to the siting of an epidural either before labour properly commences or in the early stages of it. It is advocated in patients in whom it is desirable to have one before any anticipated difficulties in labour. These include Pre-Eclampsic Toxaemia (PET) \& HELLP (Haemolysis, elevated liver enzymes and low platelets) patients, where blood results including coagulation may worsen as labour progresses, cardiac patients to reduce strain on the heart, and those with substantial risks of a General Anaesthetic (GA) (such as difficult airways or morbidly obese women).

\section{Procedure}

Prior to epidural insertion, the patient must be appropriately pre-assessed for suitability and consented for the procedure by an anaesthetist. Intravenous access must be present, as should continuous foetal and intermittent maternal monitoring. Ensuring the patient is adequately positioned is of paramount importance to the anaesthetist to improve the chances of locating the epidural space as safely as possible. Maximum lumbar flexion is desired, either in 
the seated position, or in a lateral position depending on the mother or the foetus. Strict asepsis is adhered to. A suitable space between lumbar vertebrae is located through gentle palpation of the back. If the spaces are impalpable, for example in obese patients, ultrasound may be used to assist. The epidural needle is introduced after infiltration of the surrounding skin with local anaesthetic. The needle is advanced until it is gripped by the spinal ligaments. The stylet is removed and a special loss of resistance syringe, filled with either saline or air, is attached to the end. The epidural needle is advanced, with pressure mainly applied through the syringe. The syringe is designed to be of very low resistance. This ensures that when the epidural space is located, the plunger releases, with the syringe's contents entering the space, the needle does not advance any further, thus reducing the risks of a dural puncture. A small catheter is then threaded through the epidural needle. The needle is then withdrawn, leaving the catheter in the epidural space. It is secured and a small test dose of epidural mix is given. This is to ensure the catheter has not inadvertently entered into the intrathecal space.

Different centres use varying epidural mixes and bolus regimes. A dose of $5-10 \mathrm{~mL}$ of bupivacaine, levobupivicaine or ropivicaine $(0.125-0.25 \%)$ is sufficient to begin analgesia. Subsequently, boluses may be intermittent to maintain analgesia, or a continuous infusion of $8-12 \mathrm{~mL} / \mathrm{hr}$ of $0.0625 \%-0.1 \%$ bupivacaineor $0.1 \%$ ropivicaine, often combined with low dose opiate such as fentanyl $1-2 \mathrm{mcg} / \mathrm{mL}$ or sufentanil $0.3-0.5 \mathrm{mcg} / \mathrm{mL}$.

Different pump designs have been developed that theoretically aid in epidural spread. These include automated regular intermittent boluses as opposed to continuous low volume infusion as a background. This is an area of continuous research and new innovations [5].

\section{Benefits}

A functional epidural substantially reduces pain scores in all stages of labour. However, no significant differences have been noted in overall patient satisfaction during labour [6]. One significant advantage is a resultant reduction in opiate exposure for the foetus.

Epidurals are commonly run as PCEA (Patient-Controlled Epidural Anaesthesia), whereby the mother presses a button, which delivers a bolus of analgesic mixture when she requires further relief. This gives the mother a degree of control over her analgesia and labour. It is associated with lower doses of local anaesthetic being required during labour compared to continuous infusions [7]. 'Low-dose' epidural mixes spare motor function while providing good sensory analgesia. These are often referred to as mobile epidurals. While traditionally, epidurals have been associated with an increased likelihood of instrumental delivery, use of these mixtures has negated this [8].

Conversion to surgical anaesthesia for emergency Lower Segment Caesarean Section (LSCS) can be more rapid with an epidural top up, with an operating room to incision time of up to 11 minutes. It is advantageous as the top up process may be commenced in the delivery room, provided the anaesthetist accompanies the patient into theatre. This is compared to 13 minutes for a single shot spinal. This can result in more rapid delivery in instances of foetal distress [9]. A general anaesthetic is more rapid (6minutes) [9], however is associated with significant other risks, such as aspiration, failed intubation and uterine atony [10].

For babies, when measuring umbilical cord $\mathrm{pH}$, epidurals are associated with less acidosis compared to mothers who had not had one. However, there have been no identifiable differences in APGAR score or longer-term outcomes [6].

\section{Contraindications}

Patient refusal and coagulopathy are absolute contraindications to performing an epidural. Additionally, allergy to the local anaesthetic and infection overlying the injection site are contraindications. Coagulopathy risks epidural haematoma formation, with subsequent mass effects [11]. Patients suffering from PET and gestational thrombocytopenia are particularly at risk. Mothers with these conditions need platelet count and coagulation screens within 6 hours of the epidural insertion. Care must be taken in patients receiving Low Molecular Weight Heparin (LMWH) and antiplatelets, such as those with antiphospholipid syndrome, pre-eclampsia and inpatients. Neuraxial techniques should not be attempted if LMWH prophylaxis has been administered within 12 hours, or 24 hours for treatment dose, allowing at least 4 hours since spinal puncture or catheter removal before re-administration [12]. For coumarins such as warfarin, the INR must simply be $<1.5$, while clopidogrel requires a gap of at least 7 days prior to neuraxial [12]. Table 1 summarizes the time after anticoagulant dosing for insertion and removal of epidural catheters.

Epidural insertion in septic patients is controversial. In labour, the picture is often blurred due to raised White Cell Counts (WCC) and pyrexia being found in $1 / 3$ of non-septic labouring women. Insertion of an epidural catheter in a septic patient may introduce blood borne pathogens into the epidural space, as well as lead to physiological instability in the case of relative hypovolaemia and hypotension associated with systemic infection. Severe sepsis may lead to disseminated intravascular coagulopathy (DIC), increasing the risk of epidural haematoma formation.

Epidurals in the context of raised intracranial pressure should be avoided due to the risks of cerebral herniation, should the CSF space be accidentally entered. Pre-existing CNS disorders such as Multiple Sclerosis, Motor Neuron Disease and spina bifidas may be considered reasons for not performing epidurals. Complications may occur due to difficulties in anatomy and potential worsening of neurology and the dangers of compromising respiratory function. Previous back surgery and back injuries traditionally have been listed as a relative contraindication due to the difficulties surrounding insertion, exacerbation of pre-existing deficits and increased likelihood of failed and inconsistent blocks.

Whilst epidural anaesthesia may be helpful in some cardiac patients, due to the lowering of physiological stress and a reduction in the after load, patients reliant on pre-load such as those with aortic stenosis and hypertrophic obstructive cardiomyopathy may become compromised after epidural siting. Bradycardias and hypotension are poorly tolerated in this population. More invasive monitoring may be required during the time of epidural insertion and usage, to ensure adequate cardiovascular homeostasis.

\section{Risks}

Epidural anaesthesia can be associated with an increased incidence of instrumental delivery, ranging between $9-40 \%$ of women, depending on the study and the concentration of local anaesthetic used [15]. There is also a two-fold increased risk of perineal lacerations, including $3 \mathrm{rd}$ and 4 th degree tears. There is no increased risk of requiring a Caesarean Section however. They are also associated with higher oxytocin doses required for augmentation of labour [3].

Epidurals are not always $100 \%$ effective in providing adequate labour analgesia. Incomplete analgesia may occur when dermatomal segments are missed or the block is more unilateral. Indeed, it may fail completely and require re-siting. Breakthrough pain may require 
Table 1: A table summarizing the timing of inserting and removing epidural catheters in mothers taking anticoagulants.

\begin{tabular}{|c|c|c|c|}
\hline Agent & $\begin{array}{c}\text { Time before puncture or } \\
\text { catheter removal }\end{array}$ & $\begin{array}{l}\text { Time after puncture or } \\
\text { catheter removal }\end{array}$ & Notes \\
\hline Aspirin & None & None & \\
\hline Clopidogrel & 7 days & None & $\begin{array}{l}\text { Platelet function testing may be required as } 10-20 \% \text { have Clopidogrel } \\
\text { resistance [13] }\end{array}$ \\
\hline $\begin{array}{l}\text { Coumarins (e.g., } \\
\text { Warfarin) }\end{array}$ & INR $<1.5$ & None & $\begin{array}{l}\text { Reversal with vitamin K begins immediately, but takes } 24-48 \text { hrs to fully } \\
\text { reverse. More rapid with higher doses and IV administration [14] }\end{array}$ \\
\hline LMWH (prophylaxis) & 12 hours & 4 hours & $\begin{array}{l}\text { Anti-factor Xa levels may be measured to ensure therapeutic targets } \\
\text { reached, however very little evidence on safe levels FXa levels for } \\
\text { neuraxial insertion }\end{array}$ \\
\hline LMWH (treatment) & 24 hours & 4 hours & \\
\hline UFH (prophylaxis) & 4-6 hours & 1 hour & \\
\hline UFH (treatment) & $\begin{array}{l}\text { 4-6 hours (IV) } \\
8-12 \text { hours (SC) }\end{array}$ & $\begin{array}{l}1 \text { hour } \\
1 \text { hour }\end{array}$ & \\
\hline NSAIDs & None & None & \\
\hline
\end{tabular}

supplemental medication. Sacral sparing may occur when the epidural is sited later in labour due to the lack of spread more caudally due to the pressure of the foetal head [16].

Dural puncture may occur when the large-bore epidural needle passes through the epidural space into the subarachnoid space, creating a hole. Through this, there is potential for passage of the analgesic mixture into the CSF. This may result in the level of the block progressing too high or sympathetic blockade leading to profound hypotension. Even without tapping the dura, epidurals can lower blood pressure significantly due to sympathetic blockade and a reduction in circulating catecholamines [17]. This can lead to foetal distress. For this reason, ensuring the patient has secure IV access prior to siting the epidural, and ensuring they are euvolaemic, are essential prerequisites. Continuous CTG monitoring is also strongly advised.

Neuraxial analgesia has been associated with development of maternal fevers, which in general, are not clinically significant [18]. Hyperthermia can, however, result in maternal tachycardia and increased oxygen consumption. This may be disadvantageous in some cardiac patients. Pyrexia in labour is associated with a higher intervention rate, both operative vaginal and Caesarean Section [19]. It can lead to an increased number of newborns being kept under observation and treated for possible sepsis [15].

Post-procedural risks include a severe headache that manifests between 2-5days after insertion, though may occur immediately, as a result of a CSF leak, putting traction on the meninges in the skull as the patient sits up. The quoted risk is between 1:100 to 1:50 [20]. Urinary retention is common, so mothers are often catheterised during labour. There is no increased risk of back pain following an epidural [6]. Epidural haematomas or abscesses are significant complications that may occur [21]. The most alarming risks for patients are that involving nerve damage, which may be temporary or permanent [22]. These risks are thankfully very low, in the order of 1.6 per 10,000 epidurals [23].

Other considerations involve the requirements for one-to-one midwife care whilst an epidural is in situ. Evidently, there is also a necessity for anaesthetic cover.

Figure 1 outlines a decision tree to help clinicians decide when to offer an epidural, and which patients should have an alternative technique administered.

\section{Nitrous Oxide (Entonox)}

Inhaled analgesia involves using sub-anaesthetic concentrations of inhaled Nitrous Oxide, to maintain consciousness and the laryngeal reflex. At present, it is used by $50-75 \%$ of women in labour in the UK [24]. It is delivered intermittently either via facemask or mouthpiece. A 50:50 mixture of nitrous oxide and air is the most commonly used. This comes as a pre-mixed formula (Entonox) or created via a splitting device (e.g., Nitronox).

It has been found to offer a significant reduction in labour discomfort compared to placebo [25]. Principally, it is a non-invasive therapy. It can be administered easily at very short notice, with relatively rapid onset of analgesia (30 to 60 seconds). Washout time is similarly rapid (4 to 5 breaths).It may also be used alongside epidural anaesthesia for bridging pain relief. Use of it does not increase the chances of an operative delivery. Nitrous oxide in analgesic quantities has minimal effects on the cardiovascular system and carries a very low risk of toxicity to both mother and foetus. It has no effects on uterine tone unlike other volatile anaesthetics.

Nausea and dizziness are the most common side-effects. Theoretical risks of uterine relaxation, hepato- and renal-toxicity exist but are not seen at analgesic levels [26]. There have been no reported significant effects to the foetus and APGAR scores at birth [27].

Concerns regarding prolonged exposure to healthcare staff, including hepato- and renal toxicity, and subfertility have been raised. In practice, these are not significant; however guidelines exist regarding the safe levels of exposure to healthcare workers. Nitrous oxide is a greenhouse gas thus raises environmental concerns [28].

\section{Opioids}

\section{Pethidine and diamorphine}

Parenteral opioids are given either intramuscularly or intravenously. $34 \%$ of women use an opioid during labour in the UK, $95 \%$ of UK hospitals offer IM pethidine or diamorphine and 50\% offer PCAs [29]. NICE recommendations are, however, that parenteral opioids have a limited effect on pain in labour, regardless of the opioid or route of administration [3].

Parenteral opioids may be beneficial as less invasive alternatives to neuraxial analgesia [30]. Most midwives are qualified to administer 

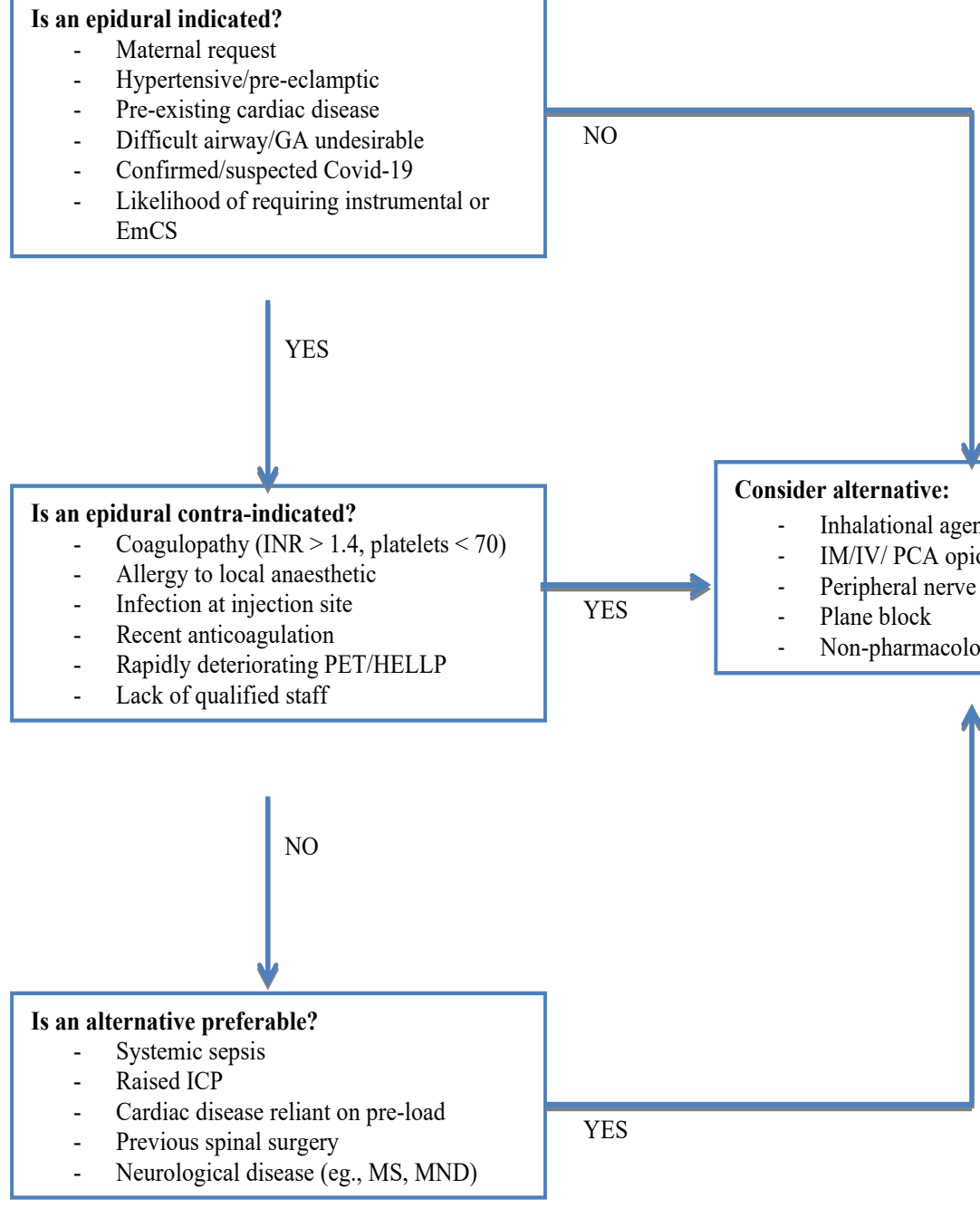

Figure 1: A decision tree to help clinicians decide the most appropriate labour analgesia technique to offer

IM pethidine or diamorphine in the UK. These are therefore available on midwife led units. They may also be given rapidly, without having to wait for an anaesthetist. This option is also helpful for those where neuraxial analgesia is technically difficult, has failed or is contraindicated.

Opioids are associated with sedative effects on both mother and foetus. These may result in impaired capacity to engage in care decisions and preclude entry into birthing pools. Drowsiness results in a reduction in mobilising, which can prolong labour and make it more painful. More importantly, it can lead to respiratory depression, requiring airway support. Uncomfortable side effects include nausea, vomiting and pruritus. Opioids delay gastric emptying, which can carry significant additional risk should general anaesthesia be required. With respect to the foetus, opioids pass readily through the placenta and may persist in the newborn for 3 to 6 days [31]. Systemic opioids have been associated with a worse acid-base status in the foetus compared to epidural anaesthesia [32] and can have profound effects on foetal heart rate (FHR) [33]. Drowsiness in the newborn can lead to a delay in breastfeeding in the perinatal period [34].
RCTs have shown a slight improvement in analgesia with diamorphine over pethidine, though labour was generally prolonged with diamorphine administration [35]. Adverse effects were comparative, apart from vomiting occurring more frequently with pethidine. APGAR scores are lower with pethidine for the first minute but show no significant differences at five minutes [36]. The breakdown product norpethidine can accumulate and potentially lower seizure threshold, although data in foetuses and new-born babies is lacking [37].

\section{Remifentanil}

The most commonly offered PCA in labour is Remifentanil based. This is a very short acting opioid which is given IV. Its effects are fast acting and easily titratable [38]. Alternatives include fentanyl and morphine, however morphine is mainly used in cases of intrauterine death (due to its longer duration of action). Remifentanil has reduced foetal-placental transfer and rapid elimination from the foetus, including in preterm infants, due to its metabolism [39]. This gives it substantial benefit over other drugs. Fentanyl has lower rates of maternal respiratory depression but significantly higher rates in the new-born [40]. However, there is significant heterogeneity in the 
literature regarding the effectiveness of Remifentanil in providing analgesia, which leads to difficulties in drawing conclusions [41]. The latest Cochrane consensus is that Remifentanil PCAs provide inferior analgesia compared to epidurals [42].

As with other opioids, maternal sedation, respiratory depression and apnoea have been widely reported [43]. As a result, they create a significant midwife workload, as constant 1:1 observation is required, as well as the presence of an experienced anaesthetist. Supplemental oxygen is required in around $50 \%$ of those receiving remifentanil [44], and its constant administration is advocated whilst the patient is receiving the PCA. Furthermore, some concerns have been raised that administration of opioids can lead to hyperalgesia following their cessation [45]. However, there is no published literature regarding subsequent hyperalgesia following Remifentanil administration in the labouring patient.

\section{Peripheral Nerve Blocks}

A paracervical block involves a submucosal injection of local anaesthetic into the vaginal fornix near the neural fibres innervating the lower uterus, cervix and upper vagina (T10-L1), as they pass through the uterovaginal (Frankenhauser's) plexus. They are rarely used now due to the increased incidence of foetal bradycardia, particularly with use of bupivacaine [46].

Blocking the pudendal nerve anaesthetises S2-S4 which supplies the vaginal vault, perineum and rectum. It is easily blocked transvaginally as the nerves loop around the ischial spines. It provides effective pain relief for the $2^{\text {nd }}$ stage when instrumental delivery is required [47], but often discomfort is still felt as the upper floor of the vagina is largely innervated by lumbar fibres. Unfortunately, it also has no effect during the first stage of labour. It may, however, be used as an adjunct to an epidural where sacral sparing has occurred.

\section{Non-Pharmacological Approaches}

Transcutaneous Electrical Nerve Stimulation (TENS) uses a device that passes a low voltage through the skin to stimulate the nerves at various frequencies and intensities. The mechanism of action is unclear, but it is thought to work through Melzack's Gate Theory of Pain [48], whereby transmission of pain is blocked by the large afferent sensory inputs. It may also work through distraction and allowing the patient a sense of greater control. A Cochrane Review concluded some benefits over placebo [6]. There are no reported significant adverse effects from using TENS.NICE, however concluded that there is no evidence TENS has analgesic benefit in established labour [3].

Hypnosis involves the mother being taught to enter into a semimeditative state, whereby some experiences are prevented from reaching conscious perception, such as fear, tension and pain during childbirth [49]. Immersion in warm water has been shown to help alleviate discomfort in labour, as well as increase uterine perfusion, reduce blood pressure and optimise the progression of the labour itself. Aromatherapy through the use of essential oils is thought to increase secretion of the body's own sedative, stimulant and relaxing neurotransmitters, which, although has no measurable physiological effects, can demonstrate a psychological improvement in mood and anxiety [50]. Acupuncture and acupressure involve either the insertion of fine needles or the application of pressure to specific parts of the body. It is unknown how its effects are produced, but it has been suggested to involve modulation of pain stimuli through the Gate Theory, or by stimulating the body to release endorphins. Reflexology works on a similar principle, involving the application of gentle pressure or manipulation of special reflex points on the body.
Massage uses manipulation of body tissues to release tension and relax and soothe the patient. It may also inhibit the sensory pathways as a gateway, and improve blood flow and oxygen to the tissues.

\section{New Innovations}

\section{Erector spinae block}

An erector spinae block is a plane block that utilizes the fascial plane beneath the muscle in the back, which contains the ventral and dorsal rami of the spinal nerves. The erector spinae muscles are composed of iliocostalis, longissimus and spinalis muscle. The ultrasound transducer is placed in the sagittal direction, around $2 \mathrm{~cm}$ off the midline. Three longitudinal muscle groups are visible; trapezius being the most superficial, followed by the rhomboids, with the erector spinaes beneath. The transverse processes of the ribs will be visible underneath. The needle is inserted in plane, until it reaches the transverse processes. Large volume local anaesthetic is injected into this area, achieving significant spread within the fascial plane, which can lead to analgesia at many dermatomal levels [51].

Whilst traditionally it has been used for chest wall surgery and rib fracture relief, it has more recently been used effectively for abdominal surgery [52]. Case reports exist of its use in women who were unable to have epidurals, and other forms of analgesia were insufficient during labour [53]. They have also been used to good effect in the post-operative period for Caesarean Sections [54]. The planes do not extend bilaterally, so require catheters to be inserted on both sides of the back. Although erector spinae blocks are likely to be less effective than traditional epidurals, they may have a place in patients unable to have epidurals. Although it does not sit in the epidural space, given its proximity to the spine, caution should be exercised with deranged clotting.

\section{Quadratus lumborum blocks}

Posterior quadratus lumborum blocks were first used in 2007. Local anaesthetic is injected into the posterior abdomen, around the quadrates lumborum muscle, to create a plane block along the transversalis facia. Spread of the anaesthetic reaches the more caudal erector spinae muscles, as well as the iliohypogastric, ilioinguinal and subcostal nerves. Anaesthesia can be achieved from T4-L1, with both somatic and visceral blockade. The patient is positioned in a lateral position, with the transducer in the axial plane on the flank in the mid-axillary line. The probe is moved in a posterior direction until the transversus abdominal muscle aponeurosis is visible under the latissimus dorsi muscle. Depending on the approach, the needle is advanced to just below the aponeurosis above the transversalis facia. Injection of local anaesthetic into this plane spreads to encircle the quadratum lumborum muscles.

There has been considerable evidence for their use as postoperative analgesia for elective caesarean sections. A recent systematic review has demonstrated a significant reduction in requirements for post-operative opioids, when an intrathecal opioid has not been administered. However, there was insufficient evidence to show significant improvement when intrathecal morphine had been given [55]. There is very little evidence for motor blockade following quadrates lumborum blocks, which is of additional value considering the importance of mobilization post-partum [56]. It has been used for labour analgesia [57]. However, due to its distribution, it only provides analgesia for the first stage of labour. It remains, however, an option for patients unable to have neuraxial procedures.

At the time of writing, there were no randomised controlled trials registered on ClinicalTrials.gov to be taking place to examine either 
Table 2: A table to summarise the advantages, disadvantages and effects on mother and foetus of various analgesic regimes during labour.

\begin{tabular}{|c|c|c|c|c|c|c|}
\hline Technique & Advantages & Disadvantages & Effects on mother & $\begin{array}{l}\text { Effects on } \\
\text { foetus }\end{array}$ & COVID Considerations & $\begin{array}{l}\text { Comparison to } \\
\text { labour epidural }\end{array}$ \\
\hline Nitrous Oxide & $\begin{array}{l}\text { Non-invasive } \\
\text { Rapid administration \& } \\
\text { effects } \\
\text { Does not require an } \\
\text { anaesthetist }\end{array}$ & $\begin{array}{l}\text { Side effects } \\
\text { Staff exposure }\end{array}$ & Nausea \& dizziness & Nil & No increased risk & $\begin{array}{l}\text { Inferior } \\
\text { analgesia }\end{array}$ \\
\hline IM/IV opiates & $\begin{array}{l}\text { Less invasive } \\
\text { Does not require an } \\
\text { anaesthetist } \\
\text { May be given when } \\
\text { epidural contraindicated }\end{array}$ & $\begin{array}{l}\text { Side effects } \\
\text { May prevent entry to } \\
\text { birthing pools }\end{array}$ & $\begin{array}{l}\text { Drowsiness } \\
\text { \& respiratory } \\
\text { depression } \\
\text { Nausea \& pruritus }\end{array}$ & $\begin{array}{l}\text { Sedation } \\
\text { Delayed } \\
\text { feeding }\end{array}$ & $\begin{array}{l}\text { Respiratory depression } \\
\text { ill-advised due to risks of } \\
\text { intubation }\end{array}$ & $\begin{array}{l}\text { Inferior } \\
\text { analgesia }\end{array}$ \\
\hline $\begin{array}{l}\text { Remifentanil } \\
\text { PCA }\end{array}$ & $\begin{array}{l}\text { Effective analgesia } \\
\text { Less invasive } \\
\text { May be given when } \\
\text { epidural contraindicated }\end{array}$ & $\begin{array}{l}\text { Requires trained nursing/ } \\
\text { midwifery care } \\
\text { Requires supplemental } \mathrm{O}_{2} \\
\text { Side effects }\end{array}$ & $\begin{array}{l}\text { Drowsiness } \\
\& \text { respiratory } \\
\text { depression }\end{array}$ & Nil & $\begin{array}{l}\text { Respiratory depression } \\
\text { ill-advised due to risks of } \\
\text { intubation }\end{array}$ & $\begin{array}{l}\text { Inferior } \\
\text { analgesia }\end{array}$ \\
\hline $\begin{array}{l}\text { Pudendal \& } \\
\text { Paracervical }\end{array}$ & $\begin{array}{l}\text { Does not require an } \\
\text { anaesthetist } \\
\text { No systemic effects } \\
\text { Rapid \& good effects } \\
\text { for instrumentals \& } \\
\text { episiotomies }\end{array}$ & No effect on $1^{\text {st }}$ stage & Painful insertion & $\begin{array}{l}\text { Foetal } \\
\text { bradycardia }\end{array}$ & No increased risk & $\begin{array}{l}\text { Inferior } \\
\text { analgesia }\end{array}$ \\
\hline
\end{tabular}

erector spinae or quadrates lumborum blocks in the labouring patient. These would be interesting studies to conduct prior to more widespread use of the techniques. Their use in caesarean section is currently under investigation through a number of studies $[58,59]$.

\section{COVID-19}

At present, there is limited evidence regarding safety of epidurals during the pandemic. Early epidural insertion has been advised to reduce the risks of converting to a $\mathrm{GA}$, which is an aerosol-generating procedure. Additional time is also required for donning PPE should an emergency delivery be required under a GA. Adequate analgesia is essential to avoid exacerbating any respiratory symptoms in a patient suffering from COVID 19 [60]. However, epidurals have been associated with profound hypotension during caesarean section in patients with concurrent COVID19 infection compared to GA [61]. Theoretical risk exists regarding seeding virus into the epidural space, however, at present there have been no reports pertaining to this.

Whilst use of nitrous oxide during the pandemic was initially considered as a potential risk for disease spread due to aerosolisation, there is currently insufficient evidence regarding this [62]. Use of IV opioids such as remifentanil has been discouraged due to the risks of respiratory depression, and subsequent potential need for intubation $[63,64]$.

\section{Conclusions}

Epidural anaesthesia remains the Gold Standard for the labouring mother, due to its efficacy and the benefits of rapid top-up for facilitating instrumental delivery or Caesarean Section. During the current global pandemic, the use of neuraxial blocks has gained further momentum in our efforts to reduce aerosol-generating procedures (AGPs).

As this paper highlights, however, there are many factors that must be considered prior to their insertion (see Figure 1). Ensuring adequate coagulation and platelet count is vital to reduce the risk of spinal haematomas. Careful deliberation is required when maternal sepsis is suspected. Pre-existing neurological disorders require additional patient counselling and discussion prior to an epidural insertion.

Alternatives, whilst providing inferior labour analgesia, are less invasive and may be given when epidurals are contraindicated or declined by the mother (see Table 2). Nitrous oxide is often the first line agent due to its ease of administration and relative safety. Parenteral opioids are less invasive approaches, however, their side effects for both the mother and foetus must be considered. Remifentanil PCAs are gaining popularity due to their minimally-invasive nature and minimal effects on the newborn. Nevertheless, their use must be strictly monitored by appropriately trained staff due to the dangers of maternal respiratory depression.

Non-pharmacological approaches have the benefits of being more 'natural' and risk-free, which may make them more appealing to some patients. Most of them can also be used in combination with other methods.

New developments in regional anaesthetic techniques with plane blocks are in their infancy. They may begin to be used more widely. Their efficacy for post-operative analgesia in Caesarean Sections has growing evidence; however their use in labour still requires further investigation. They are techniques that not all anaesthetists feel confident in performing at present, unlike epidurals, which remain a staple of training. Epidurals are a proven, effective method of labour analgesia, and will remain the first line option for most mothers.

\section{References}

1. Lowe NK (2002) The nature of labor pain. Am J Obstet Gynaecol 186: S16-S24.

2. National Health Service (2019) NHS Maternity Statistics 2018-2019. England.

3. National Institute for Clinical Excellence (2007) Intrapartum care: care of healthy women and their babies during childbirth. Royal College of OB/GYN, England. 
4. Shatil B, Smiley R (2019) Neuraxial analgesia for labour. BJA Edu 20: 96-102.

5. Sia ATH, Iyer SJ (2013) Impact of Drug Delivery Systems on Neuraxial Labor Analgesia. Curr Anesthesiol Rep 3: 275-281.

6. Jones L, Othman M, Dowswell T, Alfirevic Z, Gates S, et al. (2012) Pain management for women in labour: an overview of systematic reviews. Cochrane Database of Sys Rev 2012: CD009234.

7. Halpern S (2005) Recent advances in patient-controlled epidural analgesia for labour. Curr Opin Anaesthesiol 18: 247-251.

8. Anim-Somuah M, Smyth RM, Cyna AM, Cuthbert A (2018) Epidural versus non-epidural or no analgesia for pain management in labour. Cochrane Database of Sys Rev 5: CD000331.

9. Palmer E, Ciechanowicz S, Reeve A, Harris S, Wong DJN, et al. (2018) Operating room-to-incision interval and neonatal outcome in emergency caesarean section: a retrospective 5-year cohort study. Anaesthesia 73: 825-831.

10. Delgado C, Ring L, Mushambi MC (2020) General anaesthesia in obstetrics. BJA Edu 20: 201-207.

11. Horlocker TT, Wedel DJ, Rowlingson JC, Enneking FK, Kopp SL, et al. (2010) Regional Anaesthesia in the patient receiving antithrombotic or thrombolytic therapy. Reg Anaesthesia Pain Med 35: 64-101.

12. Gogarten W, Vandermeulen E, Van Aken H, Kozek S, Llau JV, et al. (2010) Regional anaesthesia and antithrombotic agents: recommendations of the European Society of Anaesthesiology. Eur J Anaesthesiol 27: 999-1015.

13. Dean L (2012) Clopidogrel Therapy and CYP2C19 Genotype. In: Pratt VM, McLeod HL, Rubinstein WS (eds) Medical Genetics Summaries. National Center for Biotechnology Information (US).

14. Polito NB, Kanouse E, Jones CMC, McCann M, Refaai MA, et al. (2019) Effect of Vitamin $\mathrm{K}$ administration on rate of warfarin reversal. Transfusion 59: 1202-1208.

15. Lieberman E, O'donoghue C (2002) Unintended effects of epidural analgesia during labor: a systematic review. Am J Obstet Gynaecol 186: S31-S68

16. Hess PE, Pratt SD, Lucas TP, Miller CG, Corbett T, et al. (2001) Predictors of breakthrough pain during labour epidural anaesthesia. Anesth Analg 93: 414-418.

17. Holte K, Foss NB, Svensén C, Lund C, Madsen JL, et al. (2004) Epidural anaesthesia, hypotension and changes in intravascular volume. Anaesthesiol 100: 281-286.

18. Segal S (2010) Labor epidural analgesia and maternal fever. Anesth Analg 6: 1467-1475.

19. Lieberman E, Cohen A, Lang J, Frigoletto F, Goetzl L (1999) Materna intrapartum temperature elevation as a risk factor for cesarean delivery and assisted vaginal delivery. Am J Public Health 89: 506510 .

20. de Velde MV, Schepers R, Berends N, Vandermeersch E, De Buck F (2008) Ten years of experience with accidental dural puncture and post-dural puncture headache in a tertiary obstetric anaesthesia department. Int J Obstet Anesth17: 329-335.

21. Reynolds F (2008) Neurological Infections after Neuraxial Anesthesia. Anesthesiol Clin 26: 23-52.

22. Paech MJ, Godkin R, Webster S (1998) Complications of obstetric epidural analgesia and anaesthesia: a prospective analysis of 10,995 cases. Int J Obstet Anesth 7: 5-11.
23. Auroy Y, Narchi P, Messiah A, Litt L, Rouvier B, et al. (1997) Serious complications related to regional anesthesia: results of a prospective survey in France. Anesthesiology 87: 479-486.

24. Rosen MA (2002) Nitrous oxide for relief of labor pain: a systematic review. Am J Obstet Gynecol 186: S110-S126.

25. Klomp T, van Poppel M, Jones L, Lazet J, Di Nisio M, et al. (2012) Inhaled analgesia for pain management in labour. Cochrane Database Syst Rev CD009351.

26. Sanders RD, Weimann J, Maze M (2008) Biologic effects of nitrous oxide: a mechanistic and toxicologic review. Anesthesiology 109: 707-722.

27. Likis FE, Andrews JC, Collins MR, Lewis RM, Seroogy JJ, et al. (2014) Nitrous oxide for the management of labor pain: a systematic review. Anesth Analg 118: 153-167.

28. King TL, Wong CA (2014) Nitrous oxide for labor pain: is it a laughing matter? Anesth 118: 12-14.

29. Saravanakumar K, Garstang JS, Hasan K (2007) Intravenous patientcontrolled analgesia for labour: a survey of UK practice. Int J Obstet Anesth 16: 221-225.

30. Bricker L, Lavender T (2002) Parenteral opioids for labor pain relief: a systematic review. Am J Obstet Gynecol 186: S94-S109.

31. Hogg MI, Wiener PC, Rosen M, Mapleson WW (1977) Urinary excretion and metabolism of pethidine and norpethidine in the newborn. Br J Anaesth 49: 891-899.

32. Reynolds F, Sharma SK, Seed PT (2002) Analgesia in labour and fetal acid-base balance: a meta-analysis comparing epidural with systemic opioid analgesia. BJOG 109: 1344-1353.

33. Sekhavat L, Behdad S (2009) The effects of meperidine analgesia during labor on fetal heart rate. Int J Biomed Sci 5: 59-62.

34. Ransjo-Arvidson AB, Matthiesen AS, Lilja G, Nissen E, Widstrom $A M$, et al. (2001) Maternal analgesia during labor disturbs newborn behavior: effects on breastfeeding, temperature, and crying. Birth 28: 5-12.

35. Wee MYK, Tuckey JP, Thomas PW, Burnard S (2013) A comparison of intramuscular diamorphine and intramuscular pethidine for labour analgesia: a two-centre randomised blinded controlled trial. BJOG 121: $447-456$

36. Ullman R, Smith LA, Burns E, Mori R, Dowswell T (2010) Parenteral opioids for maternal pain management in labour. Cochrane Database Syst Rev.

37. Knight B, Thomson N, Perry G (2000) Seizures due to norpethidine toxicity. Aust N Z J Med 30: 513.

38. Feldman PL (2020) Insights into the chemical discovery of Remifentanil. Anesthesiology 132: 1229-1234.

39. Welzing L, Ebenfeld S, Dlugay V, Wiesen MH, Roth B, et al. (2011) Remifentanil degradation in umbilical cord blood of preterm infants. Anesthesiology 114: 570-577.

40. Marwah R, Hassan S, Carvalho JC, Balki M (2012) Remifentanil versus fentanyl for intravenous patient-controlled labour analgesia: an observational study. Can J Anaesth 59: 246-254.

41. Yu EHY, Tran DHD, Lam SW, Irwin MG (2016) Remifentanil tolerance and hyperalgesia: short-term gain, long-term pain? Anesthesia 71 1347-1362.

42. Weibel $\mathrm{S}$, Jelting $\mathrm{Y}$, Afshari A, Pace NL, Eberhart LH, et al. (2017) Patient-controlled analgesia with remifentanil versus alternative parenteral methods for pain management in labour. Cochrane Database Syst Rev 4: CD011989. 
43. Stocki D, Matot I, Einav S, Eventov-Friedman S, Ginosar $Y$, et al. (2014) A randomized controlled trial of the efficacy and respiratory effects of patient-controlled intravenous remifentanil analgesia and patient-controlled epidural analgesia in laboring women. Anesth Analg 118: 589-597.

44. Murray H, Hodgkinson P, Hughes D (2019) Remifentanil patientcontrolled intravenous analgesia during labour: a retrospective observational study of 10 years' experience. Int J Obstet Anesth 39: 29-34.

45. Angst MS, Koppert W, Pahl I, Clark DJ, Schmelz M (2003) Short-term infusion of the mu-opioid agonist remifentanil in humans causes hyperalgesia during withdrawal. Pain 106: 49-57.

46. Palomäki O, Huhtala $\mathrm{H}$, Kirkinen $\mathrm{P}$ (2005) A comparative study of the safety of $0.25 \%$ levobupivacaine and $0.25 \%$ racemic bupivacaine for paracervical block in the first stage of labor. Acta Obstet Gynecol Scand 84: 956-961.

47. Aissaoui $Y$, Bruyère $R$, Mustapha $H$, Bry $D$, Kamili ND, et al. (2008) A randomized controlled trial of pudendal nerve block for pain relief after episiotomy. Anesth Analg 107: 625-629.

48. Melzack R, Wall PD (1965) Pain mechanisms: a new theory. Science 150: 971-979.

49. Eng YH, Cyna AM (2006) A comparison of midwives' knowledge of and attitudes to hypnosis in hospitals with and without a hypnotherapy service. Aust J Clin Hypnother Hypn 34: 17-26.

50. Stevensen C (1994) The psychophysiological effects of aromatherapy massage following cardiac surgery. Complement Ther Med 2: 27-35.

51. Forero M, Adhikary SD, Lopez H, Tsui C, Chin KJ (2016) The erector spinae plane block: A novel analgesic technique in thoracic neuropathic pain. Reg Anesth Pain Med 41: 621-627.

52. Abu Elyazed MM, Mostafa SF, Abdelghany MS, Eid GM (2019) Ultrasound-guided erector spinae plane block in patients undergoing open epigastric hernia repair: A prospective randomized controlled study. Anesth Analg 129: 235-240.

53. Hughey SB, Cole JH, Olson TF, Rivera VA (2019) Erector spinae plane block for peripartum analgesia in a patient with Tarlov cysts. Obstet Gynecol Cases Rev 6: 155
54. Hamed MA, Yassin HM, Botros JM, Abdelhady MA (2020) Analgesic efficacy of erector spinae plane block compared with intrathecal morphine after elective cesarean section: a prospective randomized controlled study. J Pain Res 13: 597-604.

55. Xu M, Tang Y, Wang J, Yang J (2020) Quadratus lumborum block for postoperative analgesia after cesarean delivery: a systematic review and meta-analysis. Int J Obstet Anesth 42: 87-98.

56. Wikner M (2017) Unexpected motor weakness following quadratus lumborum block for gynaecological laparoscopy. Anesthesia 72: 230-232.

57. de Haan JB, Tabba S, Lee LO, Ghebremichael S, Sen S, et al. (2020) Posterior Quadratus Lumborum Block for Labor Analgesia: A Case Report. A A Pract 14: e01193.

58. US National Library of Medicine, ClinicalTrials.gov Database (2020) National Institute of Health. United States.

59. US National Library of Medicine, ClinicalTrials.gov Database (2020) National Institute of Health. United States.

60. Bauer ME, Bernstein K, Dinges E, Delgado C, El-Sharawi N, et al. (2020) Obstetric Anesthesia during the COVID-19 Pandemic. Anesth Analg 131: 7-15.

61. Chen R, Zhang Y, Huang L, Cheng BH, Xia ZY, et al. (2020) Safety and efficacy of different anesthetic regimens for parturients with COVID-19 undergoing Cesarean delivery: a case series of 17 patients. Can J Anaesth 67: 655-663.

62. Society for Maternal-Fetal Medicine, Society for Obstetric and Anesthesia and Perinatology (2020) Labor and Delivery COVID-19 Considerations. United States.

63. Society for Obstetric and Anesthesia and Perinatology (2020) Interim Considerations for Obstetric Anesthesia Care related to COVID19. United States.

64. Anim-Somuah M, Smyth RMd, Cyna AM, Cuthbert A (2018) Epidural versus non-epidural or no analgesia for pain management in labour Cochrane Database Syst Rev 5: CD000331. 